\title{
Endoxifen and Other Metabolites of Tamoxifen Inhibit Human Hydroxysteroid Sulfotransferase 2A1 (hSULT2A1) ${ }^{\text {[ }}$
}

\author{
Edwin J. Squirewell, Xiaoyan Qin, and Michael W. Duffel \\ Division of Medicinal and Natural Products Chemistry, Department of Pharmaceutical Sciences and Experimental Therapeutics, \\ College of Pharmacy, University of lowa, lowa City, lowa
}

Received June 25, 2014; accepted August 25, 2014

\begin{abstract}
Although tamoxifen is a successful agent for treatment and prevention of estrogen-dependent breast cancer, its use has been limited by the low incidence of endometrial cancer. Human hydroxysteroid sulfotransferase 2A1 (hSULT2A1) catalyzes the formation of an $\alpha$-sulfooxy metabolite of tamoxifen that is reactive toward DNA, and this has been implicated in its carcinogenicity. Also, hSULT2A1 functions in the metabolism of steroid hormones such as dehydroepiandrosterone (DHEA) and pregnenolone (PREG). These roles of hSULT2A1 in steroid hormone metabolism and in generating a reactive metabolite of tamoxifen led us to examine its interactions with tamoxifen and several of its major metabolites. We hypothesized that metabolites of tamoxifen may regulate the catalytic activity of hSULT2A1, either through direct inhibition or through serving as alternate substrates for the enzyme. We found that
\end{abstract}

4-hydroxy- $\mathrm{N}$-desmethyltamoxifen (endoxifen) is a potent inhibitor of hSULT2A1-catalyzed sulfation of PREG and DHEA, with $K_{i}$ values of 3.5 and $2.8 \mu \mathrm{M}$, respectively. In the hSULT2A1catalyzed sulfation of PREG, 4-hydroxytamoxifen (4-OHTAM) and $\mathbf{N}$-desmethyltamoxifen ( $\mathrm{N}$-desTAM) exhibited $K_{\mathrm{i}}$ values of 12.7 and $9.8 \mu \mathrm{M}$, respectively, whereas corresponding $K_{\mathrm{i}}$ values of 19.4 and $17.2 \mu \mathrm{M}$ were observed with DHEA as substrate. A $K_{\mathrm{i}}$ value of $9.1 \mu \mathrm{M}$ was observed for tamoxifen- $N$-oxide with DHEA as substrate, and this increased to $16.9 \mu \mathrm{M}$ for the hSULT2A1-catalyzed sulfation of PREG. Three metabolites were substrates for hSULT2A1, with relative sulfation rates of 4-OHTAM > N-desTAM > > endoxifen. These results may be useful in interpreting ongoing clinical trials of endoxifen and in improving the design of related molecules.

\section{Introduction}

Human hydroxysteroid sulfotransferase (hSULT2A1) is a cytosolic enzyme that catalyzes the sulfation of various endogenous and exogenous molecules (Gamage et al., 2006; Duffel, 2010; James and Ambadapadi, 2013). It is highly expressed in the liver and adrenal gland, and present in other tissues as well (Rainey and Nakamura, 2008; Riches et al., 2009). Moreover, it catalyzes the sulfation of dehydroepiandrosterone (DHEA) and pregnenolone (PREG) (Falany et al., 1989), two of the most abundant circulating steroid hormones in humans. Although the detoxication of many hydrophobic xenobiotics that contain alcohol functional groups is one of the important roles of SULT2A1, the sulfation of benzylic and allylic alcohols catalyzed by this enzyme can sometimes generate bioactive electrophilic products that are reactive toward DNA and proteins (Phillips et al., 1994; Surh and Miller, 1994; Shibutani et al., 1998b; Duffel, 2010).

Tamoxifen is a selective estrogen receptor modulator that has been successfully used for decades in the treatment and more recently the prevention of estrogen-dependent breast cancer (Fisher et al., 1998; Jordan, 2003, 2007). However, there is also an increased risk for the

This investigation was supported by the National Institutes of Health National Cancer Institute [Grant R01-CA038683]

dx.doi.org/10.1124/dmd.114.059709.

SThis article has supplemental material available at dmd.aspetjournals.org. development of endometrial cancer as a side effect of tamoxifen (Bernstein et al., 1999). The carcinogenic effects of tamoxifen are complex and may include a combination of estrogen-receptor mediated hormonal effects and metabolic activation of tamoxifen metabolites to electrophiles that are genotoxic (Dowers et al., 2006). One of the major potential genotoxic species derived from tamoxifen is its $\alpha$-sulfooxy metabolite, a product derived from the cytochrome P450 (P450)catalyzed oxidation of tamoxifen to an allylic $\alpha$-hydroxy derivative that is then a substrate for hSULT2A1 (Shibutani et al., 1998a). The resulting sulfuric acid ester is a good leaving group and forms an electrophilic carbocation intermediate that reacts with nucleophilic sites on DNA, thereby forming covalent tamoxifen-DNA adducts (Shibutani et al., 1998a).

Tamoxifen is initially metabolized through oxidative reactions catalyzed by several forms of $\mathrm{P} 450$. The most abundant of these initial metabolites in humans is $\mathrm{N}$-desmethyltamoxifen (N-desTAM), which is formed via an oxidative demethylation reaction catalyzed by CYP2D6, 3A4, 1A1, and/or 1A2 (Crewe et al., 2002; Desta et al., 2004). N-desTAM is further metabolized in a reaction catalyzed by CYP2D6 to form 4-hydroxy- $N$-desmethyltamoxifen (endoxifen) (Desta et al., 2004). Endoxifen is 100 times more potent than tamoxifen as an antiestrogen and equipotent with another P450-mediated oxidative metabolite, 4-hydroxytamoxifen (4-OHTAM) (Lim et al., 2005, 2006). Although now known to be present at lower serum concentrations than

ABBREVIATIONS: DHEA, dehydroepiandrosterone; DMSO, dimethylsulfoxide; ESI, electrospray ionization; hSULT2A1, human hydroxysteroid sulfotransferase 2A1; LC, liquid chromatography; MS, mass spectrometry; N-desTAM, $N$-desmethyltamoxifen; N-desTAM-S, $N$-desmethyltamoxifen sulfamate; 4-OHTAM, 4-hydroxytamoxifen; $\alpha$-OHTAM, $\alpha$-hydroxytamoxifen; P450, cytochrome P450; PAPS, adenosine 3'-phosphate 5'-phosphosulfate; PREG, pregnenolone; SULT, sulfotransferase; 4-TAM- $\mathrm{SO}_{4}$, 4-hydroxytamoxifen sulfate; TAM, tamoxifen; TAM-NO, tamoxifen $\mathrm{N}$-oxide; TLC, thin-layer chromatography. 
endoxifen (Gjerde et al., 2012), 4-OHTAM was the first metabolite of tamoxifen (TAM) identified with a high affinity for estrogen receptors (Jordan et al., 1977). The microsomal flavin-containing monooxygenases catalyze oxidation of the tertiary amine of tamoxifen to form tamoxifen- $\mathrm{N}$-oxide (TAM-NO) (Mani et al., 1993), a metabolite that is also of recent interest due to its potential role(s) in the activity of tamoxifen (Gjerde et al., 2012). As reviewed by Brauch et al. (2009), other metabolic products of tamoxifen include sulfate and glucuronide conjugates as well as various minor metabolites.

Pharmacogenetic differences in responses to tamoxifen have been of much interest in understanding individual variability in its clinical effectiveness (Brauch et al., 2009; Ruddy et al., 2013). While such differences may be of use in individualizing dosages of tamoxifen, another strategy has been to investigate the administration of endoxifen as an antitumor drug through clinical trials (NCT01327781 and NCT01273168; ClinicalTrials.gov). Due to the involvement of hSULT2A1 in the metabolism and transport of steroid hormones and in the genotoxicity of the $\alpha$-hydroxy metabolite of TAM, we have explored the potential for metabolites of TAM to inhibit the catalytic activity of hSULT2A1. Such inhibition might prevent formation of the genotoxic $\alpha$-hydroxy metabolite in some tissues or it might alter steroid hormone homeostasis by interfering with the inactivation of steroid substrates for the enzyme. Moreover, because inhibitors of an enzyme could be exerting their effect through serving as alternate substrates, we have also examined this possibility. Thus, our study examines the interactions of endoxifen, 4-OHTAM, N-desTAM, and TAM-NO with the human hydroxysteroid sulfotransferase hSULT2A1.

\section{Materials and Methods}

Chemicals and Instruments. Thin-layer chromatography (TLC) sheets (60 A, Silica Gel $F_{254}$, and $60 \AA$ Silica Gel without indicator) were obtained from EMD Millipore (Billerica, MA). Adenosine 3'-phosphate 5'-phosphosulfate lithium salt hydrate (PAPS) was obtained from Sigma-Aldrich (St. Louis, MO) and purified upon arrival using a previously described protocol (Sekura, 1981) to a purity greater than $99 \%$ as determined by high-pressure liquid chromatography (Sheng et al., 2001). We purchased 2-mercaptoethanol, DHEA, PREG, potassium phosphate, (Z)-tamoxifen, (Z)- $N$-desmethyltamoxifen $\mathrm{HCl}$, (Z)-4-hydroxytamoxifen, and $(E / Z)$-4-hydroxy- $N$-desmethyltamoxifen hydrochloride hydrate (endoxifen) from Sigma-Aldrich at the highest available purity $(\geq 98 \%)$. $\left.{ }^{3} \mathrm{H}\right] \mathrm{DHEA}(70.5 \mathrm{Ci} / \mathrm{mmol})$, $\left[{ }^{3} \mathrm{H}\right]$ DHEA-sulfate $(63.0 \mathrm{Ci} / \mathrm{mmol})$, and $\left[{ }^{3} \mathrm{H}\right]$ pregnenolone $(22.9 \mathrm{Ci} / \mathrm{mmol})$ were obtained from Perkin Elmer (Waltham, MA). $\left[{ }^{3} \mathrm{H}\right]$ Pregnenolone sulfate $(0.20 \mathrm{Ci} / \mathrm{mmol})$ was obtained from American Radiolabeled Chemicals (St. Louis, MO). All radioactive samples were analyzed in Econo-Safe liquid scintillation cocktail (Research Products International, Mount Prospect, IL) using a PerkinElmer Tri-Carb 2900TR Liquid Scintillation Counter.

Expression and Purification of Recombinant Human SULT2A1. SULT2A1 was expressed and extracted from BL21 (DE3) Escherichia coli as previously described elsewhere (Liu et al., 2006; Gulcan et al., 2008). The enzyme was purified using DE-52 (Sigma-Aldrich) anion exchange chromatography followed by two hydroxyapatite (Bio-Rad; Hercules, CA) columns to homogeneity as determined by SDS-PAGE. Protein concentration was determined at each step of the purification process with a modified Lowry method using bovine serum albumin as a standard (Bensadoun and Weinstein, 1976). Chromatography fractions were analyzed for enzyme activity using a previously reported methylene blue assay (Nose and Lipmann, 1958; Duffel et al., 1989).

Inhibition of hSULT2A1-Catalyzed Sulfation of DHEA. Assays for the sulfation of DHEA were performed under first-order reaction kinetics as previously described elsewhere (Gulcan and Duffel, 2011). Each 200- $\mu 1$ reaction was performed at $\mathrm{pH} 7.4$ and contained $0.25 \mathrm{M}$ potassium phosphate, $0.20 \mathrm{mM}$ PAPS, and $8.3 \mathrm{mM}$ 2-mercaptoethanol. $\left[{ }^{3} \mathrm{H}\right] \mathrm{DHEA}$ and tamoxifen metabolites were dissolved in absolute ethanol, and they were added to the reaction mixture in volumes such that the final concentration of ethanol in each assay was $2 \%(\mathrm{v} / \mathrm{v})$. The reactions were initiated by the addition of purified hSULT2A $1(0.03 \mu \mathrm{g})$ and incubated for 4 minutes at $37^{\circ} \mathrm{C}$. The reactions were then terminated by the addition of $800 \mu \mathrm{l}$ of $50 \mathrm{mM}$ potassium hydroxide and $500 \mu \mathrm{l}$ of chloroform. Samples were vortexed vigorously for 20 seconds and subjected to centrifugation at $3500 \mathrm{rpm}$ for 5 minutes to separate the phases. A $100-\mu l$ aliquot of the upper aqueous phase containing $\left[{ }^{3} \mathrm{H}\right]$ DHEA-sulfate was added to $10 \mathrm{ml}$ of liquid scintillation cocktail, and the radioactivity was determined by liquid scintillation analysis.

Inhibition of hSULT2A1-Catalyzed Sulfation of Pregnenolone. Assays for the sulfation of pregnenolone were performed using the following general procedure. Each 100- $\mu 1$ assay was performed at $\mathrm{pH} 7.4$ and contained $0.25 \mathrm{M}$ potassium phosphate, $0.20 \mathrm{mM}$ PAPS, and $8.3 \mathrm{mM} \mathrm{2-mercaptoethanol.}$ $\left[{ }^{3} \mathrm{H}\right]$ Pregnenolone and tamoxifen metabolites were dissolved in absolute ethanol, and they were added to the reaction mixture in volumes such that the final concentration of ethanol in each assay was $2 \%(\mathrm{v} / \mathrm{v})$. The reactions were initiated by the addition of purified hSULT2A $1(0.03 \mu \mathrm{g})$, incubated at $37^{\circ} \mathrm{C}$ for 4 minutes, and terminated with an equal reaction volume of methanol. A $10-\mu 1$ aliquot of the resulting mixture was applied to Silica Gel 60 TLC sheets (without indicator) and developed in chloroform/methanol/acetone/acetic acid/water (80:20:40:20:10) (Fuda et al., 2002) until the solvent moved approximately $8 \mathrm{~cm}$ from the origin. The area of the TLC sheet encompassing $2-5 \mathrm{~cm}$ from the origin contained $\left[{ }^{3} \mathrm{H}\right]$ pregnenolone sulfate, and this section was excised and placed in $10 \mathrm{ml}$ of scintillation cocktail supplemented with $500 \mu \mathrm{l}$ of methanol, and the radioactivity was determined as described earlier. The location of $\left[{ }^{3} \mathrm{H}\right]$ pregnenolone sulfate on TLC sheets was previously determined with unlabeled pregnenolone sulfate. Maximum recovery of pregnenolone sulfate under these conditions was $75 \%$, and assay results were corrected for this extraction efficiency.

Analysis of Inhibition Data. Endoxifen, 4-OHTAM, N-desTAM, and TAM-NO were used as inhibitors of the sulfation of DHEA and PREG at the indicated concentrations. Data were fit to rate equations for competitive, noncompetitive, uncompetitive, or mixed inhibition using a nonlinear leastsquares algorithm in the Enzyme Kinetics Module (version 1.3) of Sigma Plot 11.0 (Systat Software, San Jose, CA), and the model with the highest value for the coefficient of determination, $r^{2}$, was selected. In cases where $r^{2}$ was not statistically significantly different, the model with the lowest corrected Akaike information criterion was selected.

Tamoxifen Metabolites as Substrates for hSULT2A1. Tamoxifen metabolites were investigated as substrates for hSULT2A1 using a previously described protocol that determines the incorporation of a radiolabeled sulfuryl moiety from $\left[{ }^{35} \mathrm{~S}\right] \mathrm{PAPS}$ into products of the reaction (Lyon et al., 1981). Each 50- $\mu \mathrm{l}$ reaction was performed at $\mathrm{pH} 7.4$ and contained $0.25 \mathrm{M}$ potassium phosphate, $0.20 \mathrm{mM}\left[{ }^{35} \mathrm{~S}\right] \mathrm{PAPS}, 8.3 \mathrm{mM}$ 2-mercaptoethanol, and the indicated concentrations of tamoxifen metabolite dissolved in dimethylsulfoxide (DMSO), with a final DMSO concentration of $2 \%(\mathrm{v} / \mathrm{v})$. The reactions were initiated by the addition of purified hSULT2A $1(0.52 \mu \mathrm{g})$, incubated for 20 minutes at $37^{\circ} \mathrm{C}$, and terminated with $50 \mu \mathrm{l}$ of methanol. A $10-\mu \mathrm{l}$ aliquot of the resulting mixture was applied to Silica Gel 60 TLC sheets (without indicator) and developed in chloroform/methanol (3:7) until the solvent migrated approximately $8 \mathrm{~cm}$ from the origin. An area of the TLC sheet $5.5 \mathrm{~cm}$ below and including the solvent front (i.e., that contained the section of the radiolabeled sulfated products) was excised and placed in $10 \mathrm{ml}$ of scintillation cocktail for determination of radioactivity. The location of the sulfated products on TLC was determined before the radiolabeled assay using synthesized standards for $4-\mathrm{TAM}^{-\mathrm{SO}_{4}}$ and $\mathrm{N}$-desmethyltamoxifen sulfamate (N-desTAM-S).

Identification of Enzyme Reaction Products by Mass Spectrometry. Products of the hSULT2A1-catalyzed sulfation of 4-OHTAM, N-desTAM, and endoxifen were identified using liquid chromatography with mass spectrometry (LC-MS) analysis performed on a Waters Q-TOF Premiere mass spectrometer (Waters Corporation, Milford, MA). Each 50- $\mu$ l reaction was performed at $\mathrm{pH} 7.4$ and used $50 \mu \mathrm{M}$ substrate in the presence of $0.25 \mathrm{M}$ potassium phosphate, $0.20 \mathrm{mM}$ PAPS, $8.3 \mathrm{mM}$ 2-mercaptoethanol, and $2 \%$ ethanol (v/v). The reactions were initiated with the addition of hSULT2A1 $(2.6 \mu \mathrm{g})$ at $37^{\circ} \mathrm{C}$ for 60 minutes and terminated with $50 \mu \mathrm{l}$ of methanol. A 10- $\mu$ l aliquot of each sample was analyzed using a Waters Aquity BEH C18 column $(2.1 \mathrm{~mm} \times 100 \mathrm{~mm}$; $1.7 \mu \mathrm{m}$ ) using a flow rate of $0.25 \mathrm{ml} / \mathrm{min}$ and $\mathrm{UV}$ analysis at $213 \mathrm{~nm}$. A linear gradient system was programmed to $40 \%$ acetonitrile with $0.1 \%(\mathrm{v} / \mathrm{v})$ formic acid for 15 minutes, $40-70 \%(\mathrm{v} / \mathrm{v})$ acetonitrile with $0.1 \%(\mathrm{v} / \mathrm{v})$ formic acid for 5 minutes, and then sustained at $70 \%$ acetonitrile with $0.1 \%$ formic acid for 10 minutes. The liquid chromatography eluate was subjected to mass spectral 
analysis (LC-MS) through an interface with an electrospray ionization (ESI) source operated in negative ion mode.

Synthesis of TAM-NO. The $N$-oxide of tamoxifen was synthesized using a procedure previously described elsewhere (Foster et al., 1980). Aqueous hydrogen peroxide $(1 \mathrm{ml}, 30 \% \mathrm{w} / \mathrm{w})$ was added to a solution of tamoxifen (15 mg, $40 \mu \mathrm{mol})$ dissolved in methanol $(3.0 \mathrm{ml})$. The reaction was stirred at room temperature for 10 hours in the dark. The resulting product was examined for homogeneity on Silica Gel $60 \mathrm{~F}_{254}$ analytical thin layer chromatography sheets developed in chloroform/methanol/ammonium hydroxide $(8: 2: 0.05)$, which revealed tamoxifen $N$-oxide $\left(R_{\mathrm{f}}=0.40\right)$, which was well separated from any residual tamoxifen $\left(R_{\mathrm{f}}=0.69\right)$. Excess hydrogen peroxide and water were removed by concentration of the sample under nitrogen, addition of $1.0 \mathrm{ml}$ of ethanol, repeating this procedure two more times, and then performing the concentration and solvent addition procedure three times using 1.0-ml aliquots of dry benzene. Afterward, the sample was dried under nitrogen and stored overnight in a vacuum desiccator over phosphorus pentoxide to afford a white solid $\left(15.3 \mathrm{mg}, 97 \%\right.$ yield). Negative ion ESI-MS $\mathrm{m} / \mathrm{z}=388.20[\mathrm{M}-\mathrm{H}]^{-}$ (calculated $\mathrm{m} / \mathrm{z}=388.2277)$; $\left[{ }^{1} \mathrm{H}\right.$ NMR: $\left(300 \mathrm{MHz}, \mathrm{CDCl}_{3}\right) \mathrm{ppm}(\delta) 0.94$ (t, $\left.3 \mathrm{H}, \mathrm{CH}_{2} \mathrm{CH}_{3}\right) ; 2.48$ (q, 2H, $\left.\mathrm{CH}_{2} \mathrm{CH}_{3}\right) ; 3.29$ [s, $6 \mathrm{H}, \mathrm{N}\left(\mathrm{CH}_{3}\right)_{2}$ ]; 3.65 (t, $2 \mathrm{H}$, $\left.\mathrm{OCH}_{2} \mathrm{CH}_{2} \mathrm{~N}\right) ; 4.69\left(\mathrm{t}, 2 \mathrm{H}, \mathrm{OCH}_{2} \mathrm{CH}_{2} \mathrm{~N}\right) ; 6.57(\mathrm{~d}, 2 \mathrm{H}, \mathrm{Ph}) ; 6.79(\mathrm{~d}, 2 \mathrm{H}, \mathrm{Ph}) ;$ 7.11-7.39 (m, Ph).] The melting point was $136-138^{\circ} \mathrm{C}$.

Synthesis of N-desTAM-S Ammonium Salt. The sulfamate of N-desTAM was prepared using sulfuryl imidazolium triflate (2,2,2-trichloroethoxysulfuryl(2-methyl)- $N$-methy-limidazolium trifate) as the sulfating reagent, and the synthesis of this reagent has been previously reported elsewhere (Ingram and Taylor, 2006; Desoky et al., 2011). We added 1,2-dimethylimidazole (14 $\mu$ l, $157 \mu \mathrm{mol})$ to a solution of N-desTAM $(28 \mathrm{mg}, 69 \mu \mathrm{mol})$ and sulfuryl imidazolium triflate $(94 \mathrm{mg}, 207 \mu \mathrm{mol})$ dissolved in dichloromethane $(5 \mathrm{ml})$. The mixture was stirred at $0^{\circ} \mathrm{C}$ for 1 hour and gradually warmed to room temperature for a 12-hour reaction, then purified on a Silica Gel 60 flash column $(1 \mathrm{~cm} \times 10 \mathrm{~cm})$ using ethyl acetate/hexanes (33:67) as mobile phase. The eluate was concentrated, dissolved in DMSO $(2 \mathrm{ml})$, and then added to a solution of ammonium formate $(52 \mathrm{mg}, 828 \mu \mathrm{mol})$ and zinc dust $(27 \mathrm{mg}$, $414 \mu \mathrm{mol}$ ) (Liu et al., 2004) in methanol $(1 \mathrm{ml})$. The reaction was stirred at room temperature for 2 hours and filtered through celite under vacuum. Methanol was removed by rotary evaporation, and DMSO was removed by freeze-drying. The resulting mixture was purified on a Silica Gel 60 flash column $(1 \mathrm{~cm} \times 10 \mathrm{~cm})$ using dichloromethane/methanol/ammonium hydroxide (20:4:1) as mobile phase. The sample was concentrated and the solvents removed to afford a yellow, flaky solid ( $28 \mathrm{mg}, 90 \%$ yield). Negative ion ESI-MS $m / z=436.1586[\mathrm{M}-\mathrm{H}]^{-}$(calculated $\left.\mathrm{m} / \mathrm{z}=436.1588\right) ;\left[{ }^{1} \mathrm{H}\right.$ NMR:

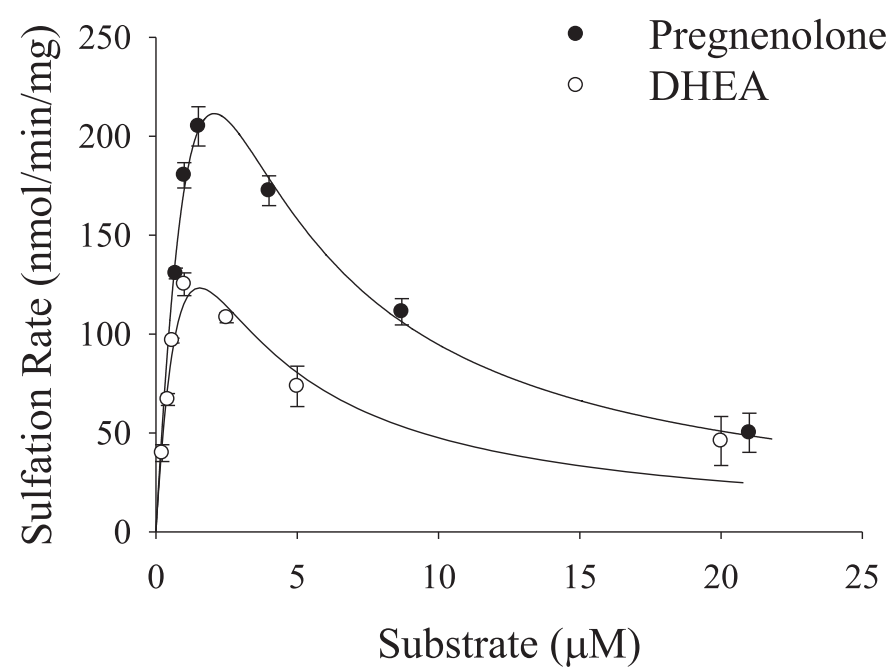

Fig. 1. Initial velocities of hSULT2A1-catalyzed sulfation of DHEA and pregnenolone in the presence of $200 \mu \mathrm{M}$ PAPS. The $K_{\mathrm{m}}$ and $V_{\max }$ for DHEA were $1.7 \mu \mathrm{M}$ and $398 \mathrm{nmol} / \mathrm{min}$ per $\mathrm{mg}$, respectively, and these values increase to $4.4 \mu \mathrm{M}$ and $1112 \mathrm{nmol} / \mathrm{min}$ per $\mathrm{mg}$ for pregnenolone sulfation. Data are mean \pm S.E. from triplicate determinations and were obtained using the same preparation of purified enzyme for both substrates. $\left(600 \mathrm{MHz}\right.$, methanol- $\left.d_{4}\right) \mathrm{ppm}(\delta) 0.92\left(\mathrm{t}, 3 \mathrm{H}, \mathrm{CH}_{2} \mathrm{CH}_{3}\right) ; 2.47$ (q, 2H, $\left.\mathrm{CH}_{2} \mathrm{CH}_{3}\right) ; 2.75$ [s, 6H, N( $\left.\left.\mathrm{CH}_{3}\right)_{2}\right] ; 3.29\left(\mathrm{t}, 2 \mathrm{H}, \mathrm{OCH}_{2} \mathrm{CH}_{2} \mathrm{~N}\right) ; 4.04(\mathrm{t}, 2 \mathrm{H}$, $\left.\mathrm{OC}_{2} \mathrm{CH}_{2} \mathrm{~N}\right) ; 6.57(\mathrm{~d}, 2 \mathrm{H}, \mathrm{Ph}) ; 6.76(\mathrm{~d}, 2 \mathrm{H}, \mathrm{Ph}) ; 7.10-7.26(\mathrm{~m}, \mathrm{Ph})$.] The melting point was $132-138^{\circ} \mathrm{C}$.

Synthesis of 4-Hydroxytamoxifen Sulfate Ammonium Salt. The sulfuric acid ester of 4-OHTAM, 4-hydroxytamoxifen sulfate (4-TAM-SO ${ }_{4}$ ), was prepared similarly to the synthesis of N-desTAM-S with slight modifications. We added 1,2-dimethylimidazole ( $2 \mu \mathrm{l}, 23 \mu \mathrm{mol})$ to a solution of (Z)-4-OHTAM $(4 \mathrm{mg}, 10 \mu \mathrm{mol})$ and sulfuryl imidazolium triflate $(14 \mathrm{mg}, 30 \mu \mathrm{mol})$ dissolved in dichloromethane $(5 \mathrm{ml})$. The mixture was stirred at $0^{\circ} \mathrm{C}$ for 1 hour and gradually warmed to room temperature for a 24 -hour reaction. The product was then purified on a Silica Gel 60 flash column $(1 \mathrm{~cm} \times 10 \mathrm{~cm})$ using chloroform/ methanol (80:20) as the mobile phase. The resulting reaction product was concentrated and then added to a solution of ammonium formate $(8 \mathrm{mg}, 120 \mu \mathrm{mol})$ and zinc $(4 \mathrm{mg}, 60 \mu \mathrm{mol})$ dissolved in methanol $(3 \mathrm{ml})$. The reaction was stirred at room temperature for 30 minutes and vacuum-filtered through celite. Afterward, the mixture was purified on a Silica Gel 60 flash column $(1 \mathrm{~cm} \times$ $10 \mathrm{~cm}$ ) using dichloromethane/methanol/ammonium hydroxide (20:4:1) as the mobile phase, and the eluate was concentrated and then lyophilized to yield a white powder ( $5 \mathrm{mg} ; 36 \%$ yield). Positive ion ESI-MS $\mathrm{m} / \mathrm{z}=468.1838$ $[\mathrm{M}+\mathrm{H}]^{+}($calculated $m / z=468.1852) ;{ }^{1} \mathrm{H}$ NMR $\left(600 \mathrm{MHz}\right.$, dimethylsulfoxide- $\left.d_{6}\right)$

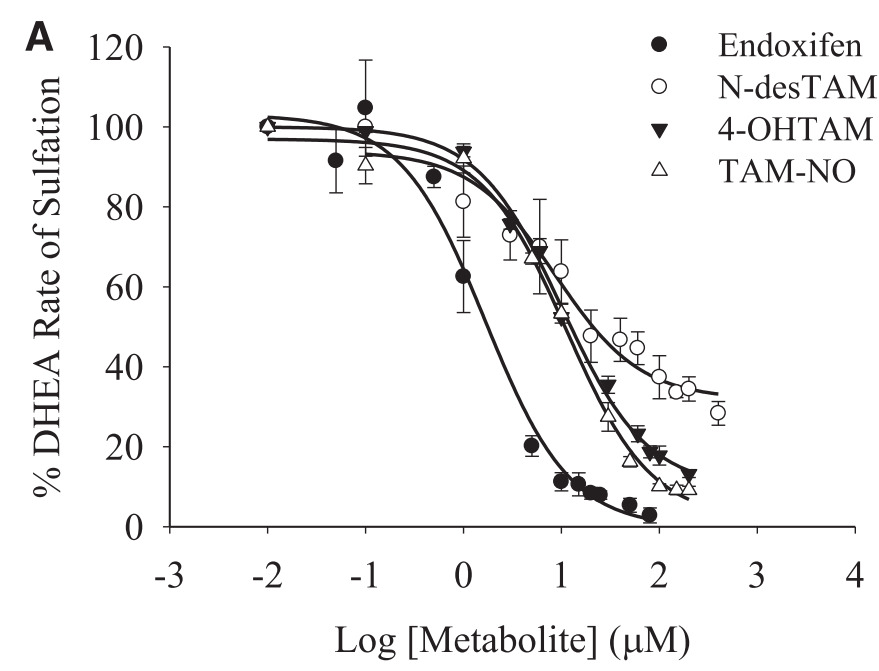

B

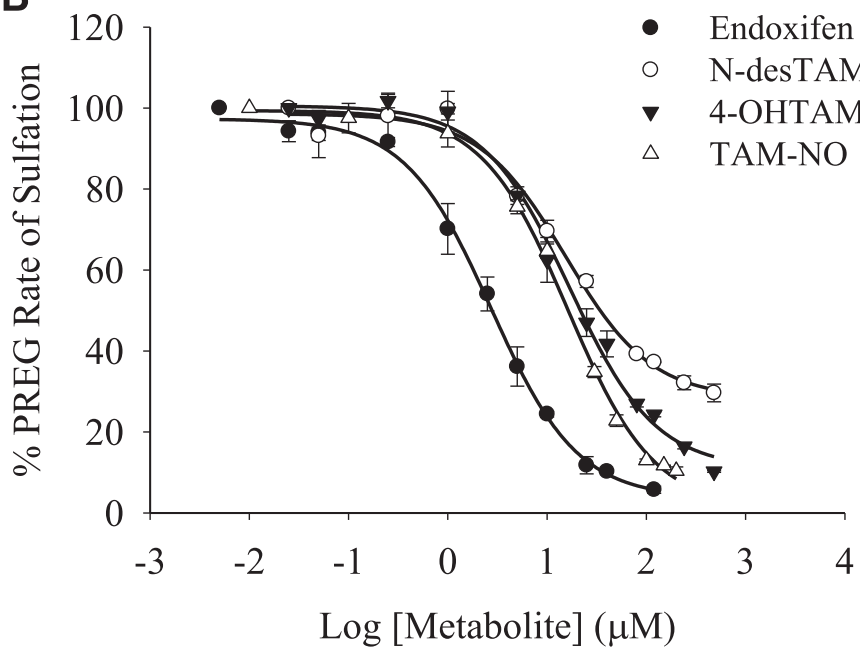

Fig. 2. Inhibition of the hSULT2A1-catalyzed sulfation of (A) $1.0 \mu \mathrm{M}$ DHEA and (B) $0.4 \mu \mathrm{M}$ pregnenolone by major metabolites of tamoxifen. Sulfation rates of uninhibited controls for endoxifen, N-desTAM, 4-OHTAM, and TAM-NO were 87, 98, 97, and $111 \mathrm{nmol} / \mathrm{min}$ per $\mathrm{mg}$, respectively, for DHEA sulfation, whereas the uninhibited rates for these metabolites were $63,92,68$, and $90 \mathrm{nmol} / \mathrm{min}$ per $\mathrm{mg}$, respectively, when determining the sulfation of pregnenolone. Data are mean \pm S.E. from triplicate determinations. 
TABLE 1

Inhibition of hSULT2A1-catalyzed sulfation of DHEA by metabolites of tamoxifen

The sulfation of DHEA was determined using $0.03 \mu \mathrm{g}$ of purified hSULT2A1 in the presence of varied concentrations of inhibitor and either $1 \mu \mathrm{M}$ DHEA (for $\mathrm{IC}_{50}$ values) or 0.22-1.0 $\mu \mathrm{M}$ DHEA for determination of the mechanism of inhibition and related kinetic constants. The data are expressed as mean \pm S.E. from three independent experiments. Calculation of $k_{\text {cat }}$ values was based on 33,678 as the subunit molecular mass of hSULT2A1.

\begin{tabular}{lrlccrr}
\hline Metabolite & \multicolumn{1}{c}{$\mathrm{IC}_{50}$} & Type of Inhibition & $V_{\max }$ & $K_{\mathrm{m}}$ & $k_{\text {cat }} / K_{\mathrm{m}}$ & \multicolumn{1}{c}{$K_{\mathrm{i}}$} \\
\hline & & & $n$ mol/min per $m g$ & $\mu M$ & $\min ^{-1} \mu M^{-1}$ & $\mu M$ \\
Endoxifen & $1.7 \pm 0.4$ & Noncompetitive & $243 \pm 17$ & $0.7 \pm 0.1$ & 10.9 & $2.8 \pm 0.2$ \\
N-desTAM & $8.3 \pm 2.6$ & Competitive & $260 \pm 24$ & $0.8 \pm 0.1$ & 11.0 & $17.2 \pm 2.0$ \\
4-OHTAM & $10.0 \pm 1.0$ & Noncompetitive & $178 \pm 7$ & $0.5 \pm 0.1$ & 11.8 & $19.4 \pm 1.6$ \\
TAM-NO & $11.1 \pm 1.1$ & Noncompetitive & $592 \pm 75$ & $3.5 \pm 0.5$ & 5.7 & $9.6 \pm 0.2$ \\
\hline
\end{tabular}

revealed an isomeric mixture of 4-TAM- $\mathrm{SO}_{4}$. [Major isomer of 4-TAM$\mathrm{SO}_{4}-\mathrm{ppm}(\delta) 0.86\left(\mathrm{t}, 3 \mathrm{H}, \mathrm{CH}_{2} \mathrm{CH}_{3}\right) ; 2.40\left(\mathrm{q}, 2 \mathrm{H}, \mathrm{CH}_{2} \mathrm{CH}_{3}\right) ; 2.69[\mathrm{~s}, 6 \mathrm{H}$, $\left.\mathrm{N}\left(\mathrm{CH}_{3}\right)_{2}\right] ; 3.26\left(\mathrm{t}, 2 \mathrm{H}, \mathrm{OCH}_{2} \underline{\mathrm{CH}}_{2} \mathrm{~N}\right) ; 4.11\left(\mathrm{t}, 2 \mathrm{H}, \overline{\mathrm{OC}}_{2} \mathrm{CH}_{2} \mathrm{~N}\right) ; 6.66(\mathrm{~d}$, $2 \mathrm{H}, \overline{\mathrm{Ph}}) ; 6.78(\mathrm{~d}, 2 \mathrm{H}, \mathrm{Ph}) ; 7.08-7.26(\mathrm{~m}, \mathrm{Ph})$.] [Minor isomer of 4-TAM$\mathrm{SO}_{4}-\mathrm{ppm}(\delta) 0.86\left(\mathrm{t}, 3 \mathrm{H}, \mathrm{CH}_{2} \mathrm{CH}_{3}\right) ; 2.40\left(\mathrm{q}, 2 \mathrm{H}, \mathrm{CH}_{2} \mathrm{CH}_{3}\right) ; 2.75[\mathrm{~s}, 6 \mathrm{H}$, $\left.\mathrm{N}\left(\mathrm{CH}_{3}\right)_{2}\right] ; 3.36\left(\mathrm{t}, 2 \mathrm{H}, \mathrm{OCH}_{2} \mathrm{CH}_{2} \mathrm{~N}\right) ; 4.28\left(\mathrm{t}, 2 \mathrm{H}, \overline{\mathrm{OC}}_{2} \mathrm{CH}_{2} \mathrm{~N}\right) ; 6.71(\mathrm{~d}$, $2 \mathrm{H}, \overline{\mathrm{Ph}}) ; 6.82(\mathrm{~d}, 2 \mathrm{H}, \mathrm{Ph}) ; 7.00(\mathrm{~d}, 2 \mathrm{H}, \mathrm{Ph}) ; 7.08-7.26(\mathrm{~m}, \mathrm{Ph})$.] Melting point: $270-275^{\circ} \mathrm{C}$

\section{Results}

Metabolites of Tamoxifen as Inhibitors of the Sulfation of DHEA and Pregnenolone Catalyzed by hSULT2A1. Tamoxifen metabolites were investigated as inhibitors of hSULT2A1 using DHEA and pregnenolone as substrates. The sulfation of either DHEA or pregnenolone was initially examined using a concentration range between 0.2 and $20.0 \mu \mathrm{M}$ for DHEA, and 0.5 and $22 \mu \mathrm{M}$ for pregnenolone to determine the substrate concentrations where minimal substrate inhibition occurred with each (Fig. 1). Under the assay conditions described, we determined that endoxifen, 4-OHTAM, $\mathrm{N}$-desTAM, and TAM-NO were all inhibitors of DHEA sulfation (Fig. 2A). Tamoxifen did not exhibit significant inhibition of hSULT2A1 up to the limits of its solubility in the assay (data not shown). Endoxifen, 4-OHTAM, and TAM-NO displayed greater than 95\% inhibition of the enzyme within their solubility limits, whereas N-desTAM reached only approximately $70 \%$ inhibition at its limit of solubility. As seen in Table 1 , the calculated $\mathrm{IC}_{50}$ (half-maximal inhibitory concentration) values ranged from 1.7 to $11.1 \mu \mathrm{M}$ for the inhibition of the sulfation of 1.0 $\mu \mathrm{M}$ DHEA, with endoxifen being the most potent inhibitor. The kinetic mechanism of inhibition, inhibitor dissociation constant $\left(K_{\mathrm{i}}\right)$, catalytic efficiency constant $\left(k_{\mathrm{cat}} / K_{\mathrm{m}}\right)$, Michaelis-Menten constant $\left(K_{\mathrm{m}}\right)$, and maximal velocity $\left(V_{\max }\right)$ for inhibitors of the hSULT2A1catalyzed sulfation of DHEA are shown in Table 1, with initial velocity data in Supplemental Fig. 1. Endoxifen, 4-OHTAM, and TAM-NO were noncompetitive inhibitors with $K_{\mathrm{i}}$ values of $2.8,19.4$, and $9.6 \mu \mathrm{M}$, respectively, whereas $\mathrm{N}$-desTAM was a competitive inhibitor of DHEA sulfation with a $K_{\mathrm{i}}$ value of $17.2 \mu \mathrm{M}$.

After our findings with DHEA, we used pregnenolone to determine whether the inhibition observed was affected by the substrate used. We found that endoxifen, 4-OHTAM, N-desTAM, TAM-NO were inhibitors of pregnenolone sulfation, and the inhibition by each metabolite was similar to our results with DHEA (Fig. 2A, 2B). The calculated $\mathrm{IC}_{50}$ values ranged from 2.7 to $16.7 \mu \mathrm{M}$ for the inhibition of $0.4 \mu \mathrm{M}$ pregnenolone, with endoxifen being the most potent inhibitor. As with DHEA as substrate, we determined the kinetic mechanism of inhibition and the kinetic parameters $V_{\max }, K_{\mathrm{m}}, K_{\mathrm{i}}$, and $k_{\text {cat }} / K_{\mathrm{m}}$ for inhibitors of the hSULT2A1-catalyzed sulfation of pregnenolone. We report these values in Table 2, with initial velocity data provided in Supplemental Fig. 2. Endoxifen, 4-OHTAM, and TAM-NO were either mixed or noncompetitive inhibitors with $K_{\mathrm{i}}$ values of $3.5,12.7$, and $16.9 \mu \mathrm{M}$, respectively, whereas the effect of N-desTAM was best described as a competitive inhibitor of pregnenolone sulfation with a $K_{\mathrm{i}}$ value of $9.8 \mu \mathrm{M}$.

Characterization of 4-OHTAM, N-desTAM, and Endoxifen as Substrates for hSULT2A1. Previous studies have shown that hSULT2A1 is capable of catalyzing the sulfation of 4-OHTAM (Falany et al., 2006). Because the $N$-sulfoconjugation of aliphatic secondary amines is catalyzed by this enzyme (Senggunprai et al., 2009), we examined the ability of hSULT2A1 to catalyze the sulfation of $\mathrm{N}$-desTAM. Moreover, because endoxifen has both a phenolic group in the 4-position as well as the secondary aliphatic amine, we also characterized the kinetics of sulfation of endoxifen. Our results showed that 4-OHTAM and N-desTAM were substrates for the enzyme (Fig. 3). The kinetics of 4-OHTAM sulfation was best described using a Michaelis-Menten equation (i.e., no substrate inhibition was evident) whereas the data for the sulfation of N-desTAM was best described using a substrate inhibition model (Fig. 3). The $K_{\mathrm{m}}, V_{\mathrm{max}}$, and $k_{\mathrm{cat}} / K_{\mathrm{m}}$ values for the sulfation of 4-OHTAM were determined to be $22.3 \pm$ $3.4 \mu \mathrm{M}, 4.9 \pm 0.1 \mathrm{nmol} / \mathrm{min}$ per $\mathrm{mg}$, and $0.015 \mathrm{~min}^{-1} \mu \mathrm{M}^{-1}$, respectively. The $K_{\mathrm{m}}, K_{\mathrm{i}}, V_{\mathrm{max}}$, and $k_{\text {cat }} / K_{\mathrm{m}}$ values for N-desTAM sulfation were

TABLE 2

Inhibition of hSULT2A1-catalyzed sulfation of pregnenolone by metabolites of tamoxifen

The sulfation of pregnenolone was determined using $0.03 \mu \mathrm{g}$ of purified hSULT2A1 in the presence of varied concentrations of inhibitor and either $0.4 \mu \mathrm{M}$ pregnenolone (for $\mathrm{IC}_{50}$ values) or 0.2-1.0 $\mu \mathrm{M}$ DHEA for determination of the mechanism of inhibition and related kinetic constants. The data are expressed as mean \pm S.E. from three independent experiments. Calculation of $k_{\text {cat }}$ values was based on 33,678 as the subunit molecular mass of hSULT2A1

\begin{tabular}{lrlcrrr}
\hline Metabolite & \multicolumn{1}{c}{$\mathrm{IC}_{50}$} & Type of Inhibition & $V_{\max }$ & $K_{\mathrm{m}}$ & $k_{\text {cat }} / K_{\mathrm{m}}$ & \multicolumn{1}{c}{$K_{\mathrm{i}}$} \\
\hline & & & nmol/min per $m g$ & $\mu M$ & $\min ^{-1} \mu M^{-1}$ & $\mu M$ \\
Endoxifen & $2.7 \pm 1.1$ & Mixed & $332 \pm 54$ & $1.2 \pm 0.3$ & 9.3 & $3.5 \pm 0.7$ \\
N-desTAM & $15.0 \pm 1.2$ & Competitive & $630 \pm 127$ & $2.1 \pm 0.5$ & 10.0 & $9.8 \pm 1.2$ \\
4-OHTAM & $16.7 \pm 1.1$ & Mixed & $522 \pm 103$ & $2.0 \pm 0.5$ & 8.5 & $12.7 \pm 2.1$ \\
TAM-NO & $16.1 \pm 1.1$ & Noncompetitive & $647 \pm 121$ & $2.3 \pm 0.5$ & 9.5 & $16.9 \pm 0.6$ \\
\hline
\end{tabular}




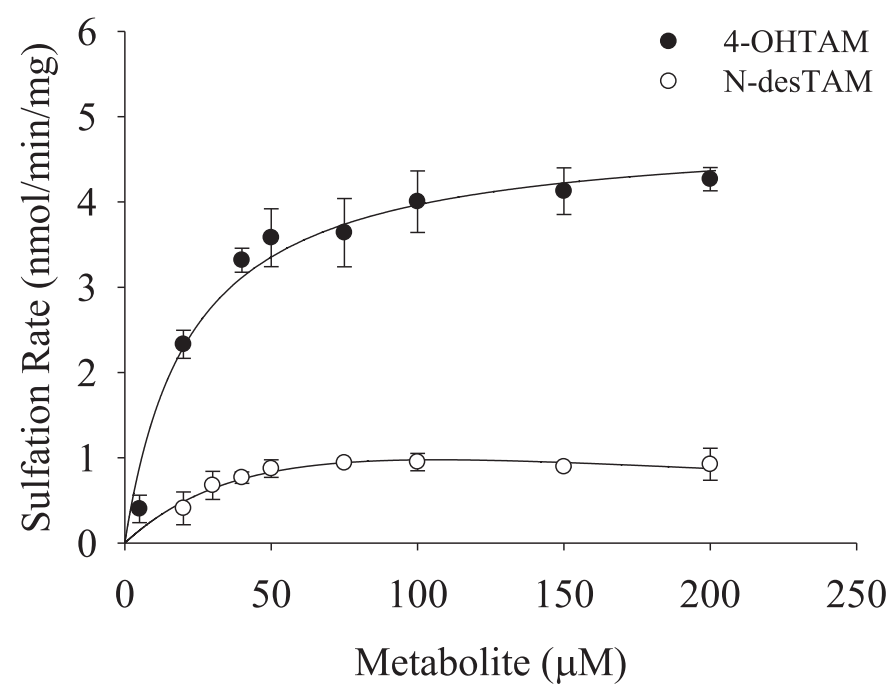

Fig. 3. Sulfation of 4-OHTAM and N-desTAM catalyzed by hSULT2A1. Data are mean \pm S.E. from triplicate determinations. Curves represent fit of the data to a simple Michaelis-Menten equation (for 4-OHTAM) and to an equation describing uncompetitive substrate inhibition (for N-desTAM).

determined to be $72.7 \pm 49.8 \mu \mathrm{M}, 156 \pm 135 \mu \mathrm{M}, 2.3 \pm 4.4 \mathrm{nmol} / \mathrm{min}$ per $\mathrm{mg}$, and $0.0024 \mathrm{~min}^{-1} \mu \mathrm{M}^{-1}$, respectively. Thus, the enzyme displayed higher catalytic activity with 4-OHTAM than with N-desTAM as seen by the 6-fold higher $k_{\text {cat }} / K_{\mathrm{m}}$.

Because the sulfamate of N-desTAM (i.e., N-desTAM-S) has not been previously reported as a metabolite, we synthesized it as a standard for analysis of N-desTAM-S formed in enzymatic reactions. The synthetic procedure for N-desTAM is outlined in Supplemental Fig. 3. We synthesized 4-hydroxytamoxifen sulfate (4-TAM-SO ${ }_{4}$ ) from (Z)-4-OHTAM, and the synthetic scheme is outlined in Supplemental Fig. 4. The proton NMR spectrum of 4-TAM- $\mathrm{SO}_{4}$ revealed evidence of both $(Z)$ and $(E)$ isomers of 4-TAM-SO ${ }_{4}$, and this was observed even though the isomeric purity of (Z)-4-OHTAM was validated by NMR before synthesizing the sulfuric acid ester of 4-OHTAM. The enzymatic reactions were analyzed by LC-MS, and the negative ion ESI-MS of the product formed by the hSULT2A1catalyzed sulfation of N-desTAM is seen in Fig. 4.

Endoxifen-sulfate was also identified as a product of sulfation catalyzed by hSULT2A1. Analysis of the enzyme-catalyzed reaction revealed a product $\mathrm{m} / \mathrm{z}$ of 452.1930 by negative ion ESI-MS (Fig. 5). Endoxifen has two potential sites for sulfation, but we were able to determine that sulfation had occurred at the phenolic hydroxyl group due to the single charge of the parent mass when analyzed in negative ion mode. Sulfation of the aliphatic amino group of endoxifen would result in a doubly charged species with an approximate $\mathrm{m} / \mathrm{z}$ of 226 , and we saw no evidence of this ion in ESI-MS analysis of our samples. The product of 4-OHTAM sulfation $\left(4-\mathrm{TAM}^{-} \mathrm{SO}_{4}\right)$ is shown in Supplemental Fig. 5 with an $\mathrm{m} / \mathrm{z}$ of 466.2050 , as determined by negative ion ESI-MS. The retention times of 4-TAM-SO $\mathrm{N}$-desTAM-S, and endoxifen-sulfate from the LC (not shown) were 16.26, 22.38, and 16.05 minutes, respectively.

N-desTAM-S and 4-TAM-SO 4 as Inhibitors of DHEA Sulfation Catalyzed by hSULT2A1. As seen in Fig. 6, N-desTAM-S was a potent inhibitor of DHEA sulfation. The calculated values for $\mathrm{IC}_{50}$ and $K_{\mathrm{i}}$ for inhibition of the enzyme were 7.7 and $4.8 \mu \mathrm{M}$, respectively. We determined 4-TAM-SO $\mathrm{SO}_{4}$ to be a very weak inhibitor of the enzyme, with an $\mathrm{IC}_{50}$ value greater than $70 \mu \mathrm{M}$ when examined with 1.0 $\mu \mathrm{M}$ DHEA as substrate (data not shown).

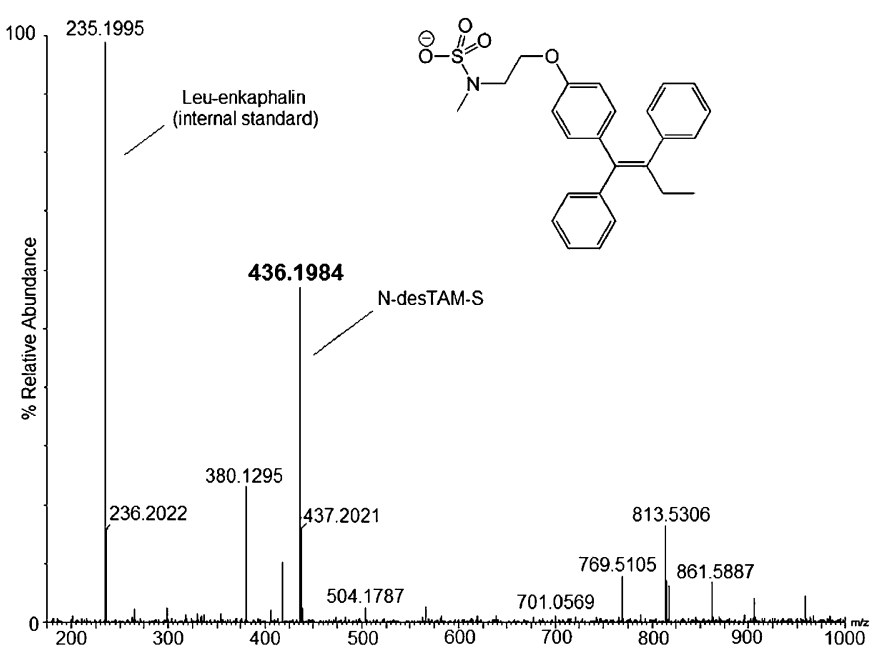

Fig. 4. LC-MS analysis of N-desTAM-S formed in a reaction catalyzed by hSULT2A1.

\section{Discussion}

The full benefits of tamoxifen as a breast cancer therapeutic agent are compromised by its low incidence of endometrial cancer (Fornander et al., 1993; Kedar et al., 1994), and the formation of genotoxic tamoxifen-DNA adducts has been proposed to be a key step in this carcinogenic response (Shibutani et al., 1999). A major mechanism for this genotoxicity begins with the cytochrome P450-mediated oxidation of tamoxifen to $\alpha$-hydroxytamoxifen ( $\alpha$-OHTAM), which then undergoes sulfation catalyzed by hSULT2A1 to form an electrophilic $\alpha$-sulfooxy intermediate that reacts with DNA to form covalent adducts (Shibutani et al., 1998a). Other mechanisms, such as those involving ortho-quinone and quinone-methide derivatives of 4-OHTAM, have also been explored as potentially responsible for toxicities seen with tamoxifen (Dowers et al., 2006).

An involvement of this hSULT2A1-mediated mechanism for the initiation of endometrial cancer by tamoxifen is consistent with several findings. First, there is evidence of hSULT2A1 mRNA expression in endometrial tissue (Singh et al., 2008), and immunohistochemical localization of the enzyme in specific cell-types within human endometrium has been reported (Andersson et al., 2010). Furthermore, in vitro studies have shown the ability of the enzyme to catalyze formation of $\alpha$-tamoxifen sulfate, with subsequent DNA-adduct formation (Shibutani et al., 1998b).

The role of hSULT2A1 in TAM-induced endometrial cancer, however, remains controversial. For example, one study failed to detect catalytic activities of hSULT2A1 in cytosolic preparations from human endometrium (Rubin et al., 1999). There is also a controversy with respect to the formation of tamoxifen-DNA adducts. Although several studies have found tamoxifen-DNA adducts in endometrial tissue from women treated with tamoxifen (Hemminki et al., 1996; Shibutani et al., 2000; Hernandez-Ramon et al., 2014) or from incubation of tamoxifen with human endometrial explants (Andersson et al., 2010), there are other reports that such adducts were not detected in endometrium (Carmichael et al., 1996, 1999; Beland et al., 2004). As recently reviewed, there is clear evidence for involvement of estrogens in endometrial carcinogenesis (Rižner, 2013), and several metabolites of tamoxifen have been shown to have estrogen agonist properties (Jordan and Gosden, 1982; Jordan, 2007). Thus, it has been hypothesized that the combination of genotoxicity due to formation of tamoxifen-DNA adducts, deficiencies in DNA repair, and estrogenic effects all combine to contribute to the risk of endometrial cancer after treatment with tamoxifen (Hernandez-Ramon et al., 2014). 


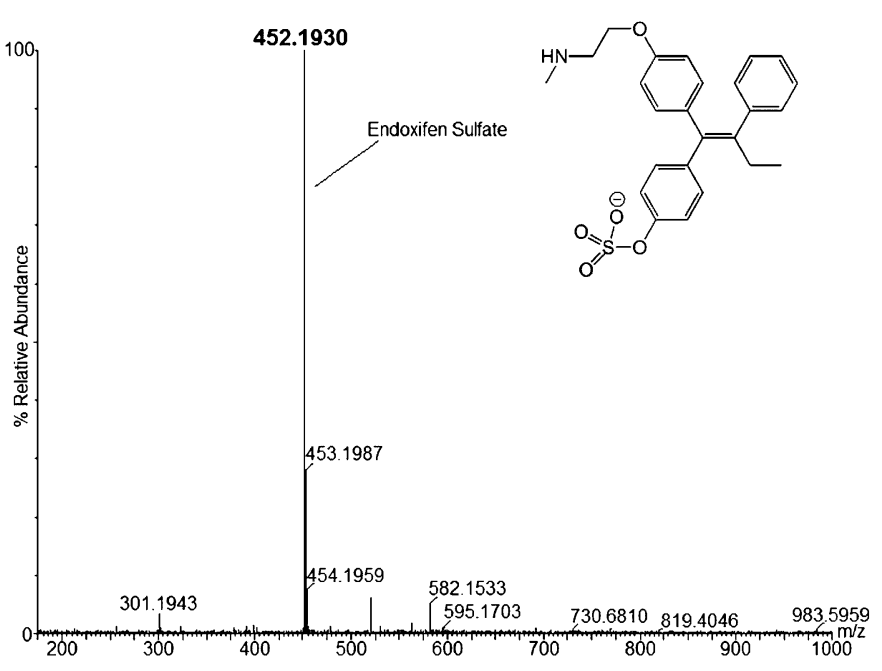

Fig. 5. LC-MS analysis of endoxifen-sulfate formed in a reaction catalyzed by hSULT2A1.

In addition to metabolic sulfation of tamoxifen metabolites and other xenobiotics, hSULT2A1 catalyzes the sulfation of DHEA to form DHEA-sulfate, one of the most abundant circulating steroid hormones in humans. DHEA-sulfate is hydrolyzed to the parent alcohol in peripheral tissues where it serves as a precursor for the biosynthesis of both estrogens and androgens. Thus, hSULT2A1 is important in maintaining the homeostasis of these steroid hormones, and inhibition by metabolites of tamoxifen might be expected to affect androgen or estrogen synthesis in a tissue-specific manner. Such alterations in cellular steroid hormones, either systemically or at the level of individual tissues, may have consequences that relate to either therapeutic or toxic effects of tamoxifen and its metabolites.

Given the complexity of the carcinogenic response to tamoxifen and the potential role(s) of hSULT2A1, we were interested in the determining the interactions of tamoxifen and its major metabolites with hSULT2A1. We hypothesized that the major metabolites of tamoxifen could inhibit the catalytic activity of hSULT2A1 and thus serve as potential modulators of the function of this enzyme in steroid hormone metabolism and in the genotoxicity of tamoxifen. Of the metabolites tested, endoxifen was the most potent inhibitor of the sulfation of $1.0 \mu \mathrm{M}$ DHEA and $0.4 \mu \mathrm{M}$ pregnenolone with $\mathrm{IC}_{50}$ values of 1.7 and $2.7 \mu \mathrm{M}$, respectively (Tables 1 and 2). This was an interesting finding because the inhibition constants for interactions between the hSULT2A1 and endoxifen were of similar magnitude to the $K_{\mathrm{m}}$ values observed for the sulfation of DHEA and pregnenolone. The range of serum concentrations reported for DHEA and pregnenolone are between 5 and $24 \mathrm{nM}$, and 1 and $6 \mathrm{nM}$, respectively (Labrie et al., 1997), whereas the mean plasma concentrations of tamoxifen metabolites have been reported to be in the general range of $14-130 \mathrm{nM}$ for endoxifen, 3-17 nM for 4-OHTAM, 15-24 nM for TAM-NO, and 280-800 nM for $\mathrm{N}$-desTAM (Brauch et al., 2009). If the serum concentrations of DHEA, pregnenolone, and the tamoxifen metabolites are an indication of their concentrations in peripheral tissues, then the metabolites have a potential to alter the homeostasis of steroid hormones by inhibiting their sulfation catalyzed by hSULT2A1. These effects would be amplified if the intracellular concentrations of the metabolites were to exceed those of the hydroxysteroids, and some studies report that the concentrations of tamoxifen metabolites in tissues are 6- to 60-fold higher than those in serum (Lien et al., 1991; Decensi et al., 2003).

Because endoxifen, 4-OHTAM, N-desTAM, and TAM-NO effectively inhibited hSULT2A1, we expect that in some cellular environments where
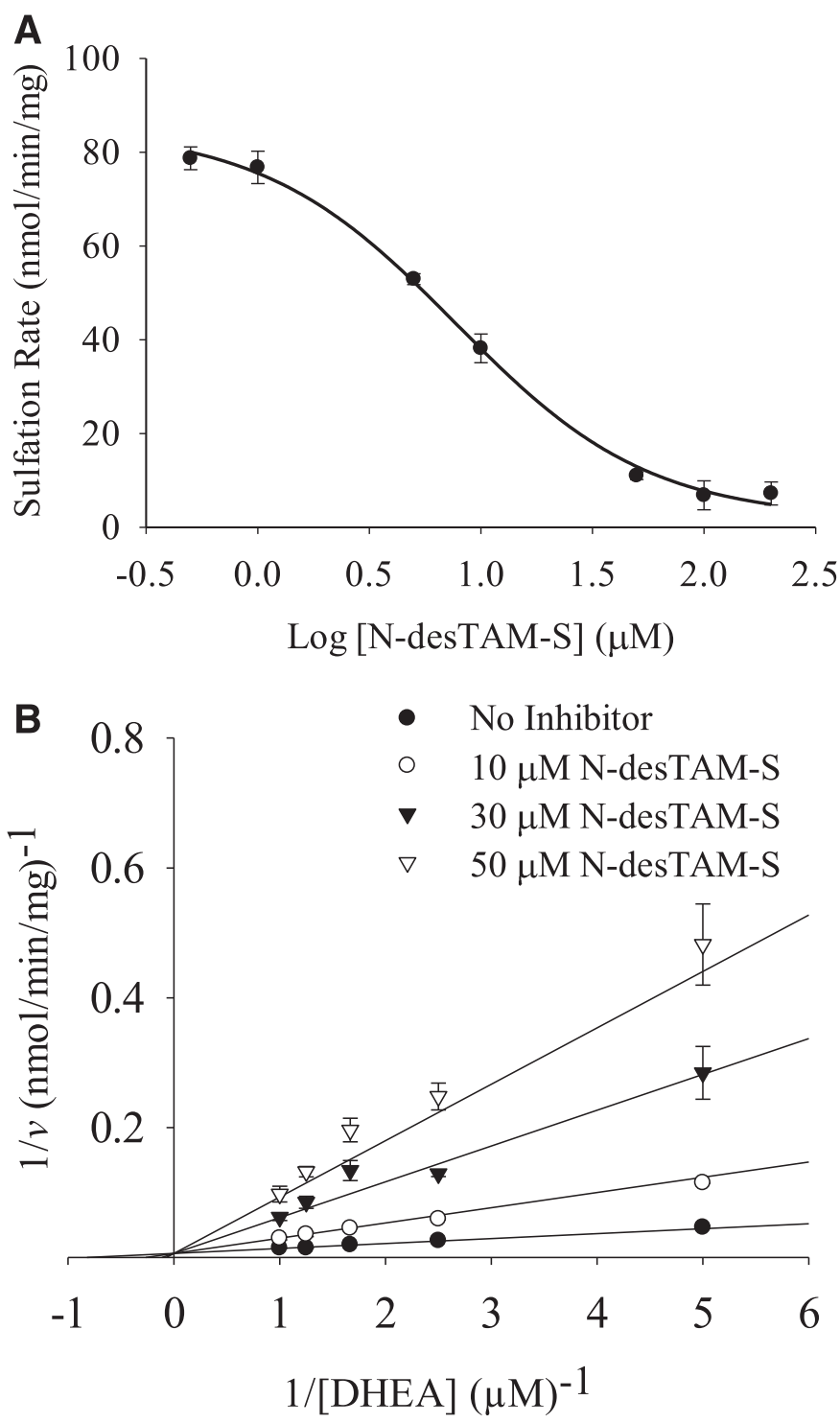

Fig. 6. Inhibition of the hSULT2A1-catalyzed sulfation of (A) $1.0 \mu \mathrm{M}$ DHEA by $\mathrm{N}$-desTAM-S with an $\mathrm{IC}_{50}$ value of $7.7 \pm 1.2 \mu \mathrm{M}$, and (B) competitive inhibition by N-desTAM-S with values for $K_{\mathrm{i}}, K_{\mathrm{m}}$, and $V_{\max }$ determined to be $4.8 \pm 0.3 \mu \mathrm{M}, 1.2 \pm$ $0.2 \mu \mathrm{M}$, and $159 \pm 15 \mathrm{nmol} / \mathrm{min}$ per $\mathrm{mg}$, respectively. Data are mean \pm S.E. from triplicate determinations.

these metabolites are produced sufficient concentrations may be present to inhibit the hSULT2A1-catalyzed sulfation of $\alpha$-OHTAM. In fact, hSULT2A1 has a much lower catalytic efficiency with $\alpha$-OHTAM than with DHEA (Apak and Duffel, 2004), and $\alpha$-OHTAM is reported to have a mean plasma concentration of only $1 \mathrm{nM}$ (Brauch et al., 2009). In the present study, endoxifen was an inhibitor of hSULT2A1 with $K_{\mathrm{i}}$ values of 2.8 and $3.5 \mu \mathrm{M}$, respectively, for DHEA and pregnenolone as substrates. We previously determined a $K_{\mathrm{m}}$ value of $136 \pm 7 \mu \mathrm{M}$ for the sulfation of $E$-( \pm )- $\alpha$-OHTAM catalyzed by hSULT2A 1 with a $k_{\text {cat }} / K_{\mathrm{m}}$ value of $5.1 \pm$ 0.3 (Apak and Duffel, 2004). Thus, it would be expected that endoxifen could inhibit the sulfation of $\alpha$-OHTAM under the appropriate in vivo conditions. Furthermore, we identified N-desTAM-S as a potent inhibitor of DHEA sulfation with a $K_{\mathrm{i}}$ value of $4.8 \mu \mathrm{M}$ (Fig. 6B), which was significantly lower than that seen for the parent metabolite. The combination of N-desTAM serving as a substrate (i.e., binding in a catalytically productive conformation at the active site) and the affinity of the enzyme for the product sulfamate suggest that N-desTAM may also contribute to inhibition of hSULT2A1. 


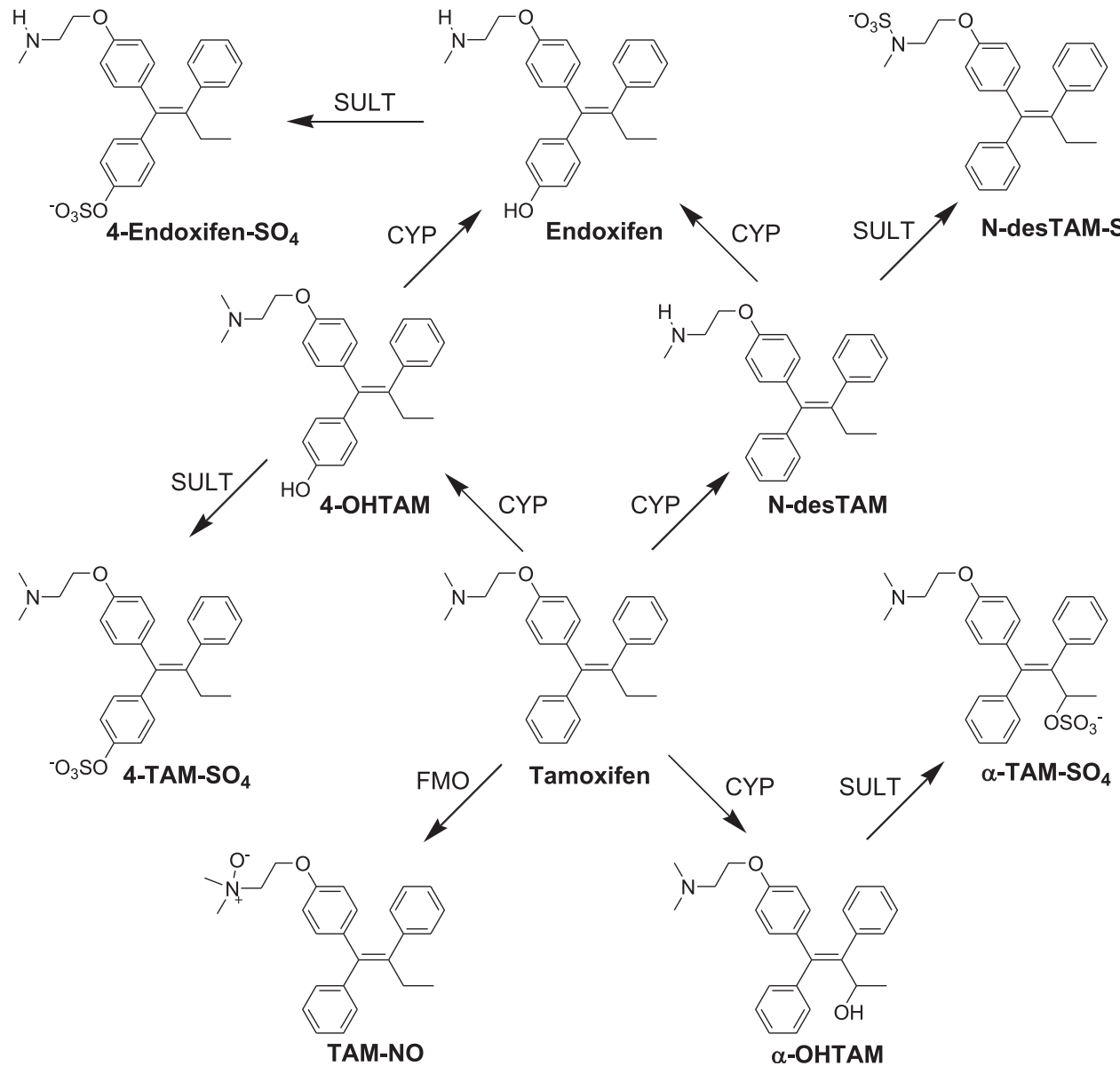

Fig. 7. Summary of the roles of sulfotransferases in the metabolism of tamoxifen and endoxifen shown within the context of pathways for formation of those metabolites of tamoxifen examined in the current study. CYP, cytochrome P450 monooxygenase; 4-Endoxifen-SO $\mathrm{S}_{4}$, endoxifen-4-sulfate; FMO, microsomal flavin-containing monooxygenase; $\alpha$-TAM-SO ${ }_{4}, \alpha$-tamoxifen sulfate.
The benefits of tamoxifen therapy depend on the in vivo formation of its active metabolites 4-OHTAM and endoxifen, which are derived from the CYP2D6-mediated oxidation of tamoxifen (Dehal and Kupfer, 1997) and N-desTAM (Brauch et al., 2009), respectively. Polymorphisms in CYP2D6 have been shown to result in lower plasma levels of endoxifen and to increase the risk of breast cancer mortality in tamoxifen-treated women (Lammers et al., 2010). To overcome the pharmacogenetic variability between tamoxifen users, endoxifen has been proposed as an independent therapeutic agent for the treatment of patients with estrogen receptor-positive breast tumors and hormone receptor-positive solid tumors (NCT01327781 and NCT01273168; ClinicalTrials.gov). Our current results suggest that an additional advantage of the direct use of endoxifen might be the lack of conversion to reactive intermediates analogous to $\alpha$-tamoxifen sulfate through inhibition of the sulfation of any $\alpha$-hydroxy metabolite that might be formed. It remains to be determined if this is a beneficial effect of the clinical use of endoxifen, but it also remains to be seen whether the observed inhibition of sulfation of endogenous steroid hormones by endoxifen has any effect on either therapeutics or toxicity.

It must be recognized, however, that the role of sulfation in the endometrium is broader than just those reactions where hSULT2A1 is involved. A brief summary of metabolic pathways involving sulfation of tamoxifen metabolites is seen in Fig. 7. Those metabolic reactions noted in Fig. 7 as being catalyzed by sulfotransferases (SULTs), as also with the reactions catalyzed by $\mathrm{P} 450 \mathrm{~s}$, may represent involvement of one or more enzyme isoforms. Indeed, previous studies have indicated the presence of SULT1A1, SULT1A3, and SULT1E1 in normal human endometrium (Rubin et al., 1999). Interactions with multiple SULTs may be important in regulating active levels of tamoxifen metabolites with either antagonist or agonist properties at estrogen receptors. Although the sulfation of 4-OHTAM is catalyzed by multiple isoforms of sulfotransferase (Falany et al., 2006), a full appreciation of the varied roles of sulfation in the metabolism of tamoxifen will require further studies on the specificities and inhibition of the individual SULTs as they relate to cellular concentrations of pharmacologically/toxicologically active metabolites.

In summary, we determined that 4-OHTAM, TAM-NO, N-desTAM, and endoxifen were inhibitors of the sulfation of DHEA and pregnenolone catalyzed by hSULT2A1. Endoxifen was the most potent inhibitor of the enzyme, which suggests that this metabolite may affect the roles of hSULT2A1 in steroid hormone metabolism and in a metabolic pathway for genotoxicity that involves this enzyme. N-desTAM was a substrate for hSULT2A1, and the product of this reaction, N-desTAM-S, displayed greater inhibition of the enzyme than its unconjugated precursor. Thus, endoxifen, $\mathrm{N}$-desTAM, and N-desTAM-S might serve protective roles in some tissues as they may inhibit the sulfation of $\alpha$-OHTAM. A more complete understanding of the interactions of tamoxifen metabolites with sulfotransferase-dependent pathways for steroid hormone metabolism and drug toxicities will await additional in vitro and in vivo studies.

\section{Authorship Contributions}

Participated in research design: Squirewell, Qin, Duffel.

Conducted experiments: Squirewell, Qin.

Performed data analysis: Squirewell, Duffel.

Wrote or contributed to the writing of the manuscript: Squirewell, Qin, Duffel. 


\section{References}

Andersson H, Helmestam M, Zebrowska A, Olovsson M, and Brittebo E (2010) Tamoxifeninduced adduct formation and cell stress in human endometrial glands. Drug Metab Dispos 38: 200-207.

Apak TI and Duffel MW (2004) Interactions of the stereoisomers of alpha-hydroxytamoxifen with human hydroxysteroid sulfotransferase SULT2A1 and rat hydroxysteroid sulfotransferase STa. Drug Metab Dispos 32:1501-1508.

Beland FA, Churchwell MI, Doerge DR, Parkin DR, Malejka-Giganti D, Hewer A, Phillips DH, Carmichael PL, Gamboa da Costa G, and Marques MM (2004) Electrospray ionization-tandem mass spectrometry and 32P-postlabeling analyses of tamoxifen-DNA adducts in humans. J Nat Cancer Inst 96:1099-1104.

Bensadoun A and Weinstein D (1976) Assay of proteins in the presence of interfering materials. Anal Biochem 70:241-250

Bernstein L, Deapen D, Cerhan JR, Schwartz SM, Liff J, McGann-Maloney E, Perlman JA, and Ford L (1999) Tamoxifen therapy for breast cancer and endometrial cancer risk. J Nat Cancer Inst 91:1654-1662.

Brauch H, Mürdter TE, Eichelbaum M, and Schwab M (2009) Pharmacogenomics of tamoxifen therapy. Clin Chem 55:1770-1782.

Carmichael PL, Sardar S, Crooks N, Neven P, Van Hoof I, Ugwumadu A, Bourne T, Tomas E, Hellberg P, and Hewer AJ, et al. (1999) Lack of evidence from HPLC 32P-post-labelling for tamoxifen-DNA adducts in the human endometrium. Carcinogenesis 20:339-342.

Carmichael PL, Ugwumadu AH, Neven P, Hewer AJ, Poon GK, and Phillips DH (1996) Lack of genotoxicity of tamoxifen in human endometrium. Cancer Res 56:1475-1479.

Crewe HK, Notley LM, Wunsch RM, Lennard MS, and Gillam EMJ (2002) Metabolism of tamoxifen by recombinant human cytochrome P450 enzymes: formation of the 4-hydroxy, 4 '-hydroxy and N-desmethyl metabolites and isomerization of trans-4-hydroxytamoxifen. Drug Metab Dispos 30:869-874.

Decensi A, Robertson C, Viale G, Pigatto F, Johansson H, Kisanga ER, Veronesi P, Torrisi R, Cazzaniga M, and Mora S, et al. (2003) A randomized trial of low-dose tamoxifen on breast cancer proliferation and blood estrogenic biomarkers. J Natl Cancer Inst 95:779-790.

Dehal SS and Kupfer D (1997) CYP2D6 catalyzes tamoxifen 4-hydroxylation in human liver. Cancer Res 57:3402-3406.

Desoky AY, Hendel J, Ingram L, and Taylor SD (2011) Preparation of trifluoroethyl- and phenylprotected sulfates using sulfuryl imidazolium salts. Tetrahedron 67:1281-1287 DOI: 10.1016/j. tet.2010.11.085.

Desta Z, Ward BA, Soukhova NV, and Flockhart DA (2004) Comprehensive evaluation of tamoxifen sequential biotransformation by the human cytochrome P450 system in vitro: prominent roles for CYP3A and CYP2D6. J Pharmacol Exp Ther 310:1062-1075.

Dowers TS, Qin ZH, Thatcher GR, and Bolton JL (2006) Bioactivation of selective estrogen receptor modulators (SERMs). Chem Res Toxicol 19:1125-1137.

Duffel MW (2010) Sulfotransferases, in Comprehensive Toxicology, Vol. 4 Biotransformation (McQueen CA and Guengerich FP, eds) pp 367-384, Elsevier, Oxford, United Kingdom.

Duffel MW, Binder TP, and Rao SI (1989) Assay of purified aryl sulfotransferase suitable for reactions yielding unstable sulfuric acid esters. Anal Biochem 183:320-324.

Falany CN, Vazquez ME, and Kalb JM (1989) Purification and characterization of human liver dehydroepiandrosterone sulphotransferase. Biochem J 260:641-646.

Falany JL, Pilloff DE, Leyh TS, and Falany CN (2006) Sulfation of raloxifene and 4-hydroxytamoxifen by human cytosolic sulfotransferases. Drug Metab Dispos 34:361-368.

Fisher B, Costantino JP, Wickerham DL, Redmond CK, Kavanah M, Cronin WM, Vogel V, Robidoux A, Dimitrov N, and Atkins J, et al. (1998) Tamoxifen for prevention of breast cancer: report of the National Surgical Adjuvant Breast and Bowel Project P-1 Study. J Natl Cancer Inst 90:1371-1388.

Fornander T, Hellström AC, and Moberger B (1993) Descriptive clinicopathologic study of 17 patients with endometrial cancer during or after adjuvant tamoxifen in early breast cancer. J Natl Cancer Inst 85:1850-1855.

Foster AB, Griggs LJ, Jarman M, van Maanen JM, and Schulten HR (1980) Metabolism of tamoxifen by rat liver microsomes: formation of the N-oxide, a new metabolite. Biochem Pharmacol 29:1977-1979.

Fuda H, Lee YC, Shimizu C, Javitt NB, and Strott CA (2002) Mutational analysis of human hydroxysteroid sulfotransferase SULT2B1 isoforms reveals that exon 1B of the SULT2B1 gene produces cholesterol sulfotransferase, whereas exon 1A yields pregnenolone sulfotransferase. J Biol Chem 277:36161-36166.

Gamage N, Barnett A, Hempel N, Duggleby RG, Windmill KF, Martin JL, and McManus ME (2006) Human sulfotransferases and their role in chemical metabolism. Toxicol Sci $\mathbf{9 0}$ $5-22$

Gjerde J, Gandini S, Guerrieri-Gonzaga A, Haugan Moi LL, Aristarco V, Mellgren G, Decensi A, and Lien EA (2012) Tissue distribution of 4-hydroxy- $N$-desmethyltamoxifen and tamoxifen-Noxide. Breast Cancer Res Treat 134:693-700.

Gulcan HO and Duffel MW (2011) Substrate inhibition in human hydroxysteroid sulfotransferase SULT2A1: studies on the formation of catalytically non-productive enzyme complexes. Arch Biochem Biophys 507:232-240.

Gulcan HO, Liu Y, and Duffel MW (2008) Pentachlorophenol and other chlorinated phenols are substrates for human hydroxysteroid sulfotransferase hSULT2A1. Chem Res Toxicol 21 $1503-1508$.

Hemminki K, Rajaniemi H, Lindahl B, and Moberger B (1996) Tamoxifen-induced DNA adducts in endometrial samples from breast cancer patients. Cancer Res 56:4374-4377.

Hernandez-Ramon EE, Sandoval NA, John K, Cline JM, Wood CE, Woodward RA, and Poirier MC (2014) Tamoxifen-DNA adduct formation in monkey and human reproductive organs. Carcinogenesis 35:1172-1176.

Ingram LJ and Taylor SD (2006) Introduction of 2,2,2-trichloroethyl-protected sulfates into monosaccharides with a sulfuryl imidazolium salt and application to the synthesis of sulfated carbohydrates. Angew Chem Int Ed Engl 45:3503-3506.

James MO and Ambadapadi S (2013) Interactions of cytosolic sulfotransferases with xenobiotics. Drug Metab Rev 45:401-414.
Jordan VC (2003) Antiestrogens and selective estrogen receptor modulators as multifunctional medicines. 1. Receptor interactions. J Med Chem 46:883-908.

Jordan VC (2007) New insights into the metabolism of tamoxifen and its role in the treatment and prevention of breast cancer. Steroids 72:829-842.

Jordan VC, Collins MM, Rowsby L, and Prestwich G (1977) A monohydroxylated metabolite of tamoxifen with potent antioestrogenic activity. $J$ Endocrinol 75:305-316.

Jordan VC and Gosden B (1982) Importance of the alkylaminoethoxy side-chain for the estrogenic and antiestrogenic actions of tamoxifen and trioxifene in the immature rat uterus. $\mathrm{Mol}$ Cell Endocrinol 27:291-306.

Kedar RP, Bourne TH, Powles TJ, Collins WP, Ashley SE, Cosgrove DO, and Campbell S (1994) Effects of tamoxifen on uterus and ovaries of postmenopausal women in a randomised breast cancer prevention trial. Lancet 343:1318-1321.

Labrie F, Bélanger A, Cusan L, Gomez J-L, and Candas B (1997) Marked decline in serum concentrations of adrenal C19 sex steroid precursors and conjugated androgen metabolites during aging. J Clin Endocrinol Metab 82:2396-2402.

Lammers LA, Mathijssen RH, van Gelder T, Bijl MJ, de Graan AJ, Seynaeve C, van Fessem MA, Berns EM, Vulto AG, and van Schaik RH (2010) The impact of CYP2D6-predicted phenotype on tamoxifen treatment outcome in patients with metastatic breast cancer. Br J Cancer 103 765-771.

Lien EA, Solheim E, and Ueland PM (1991) Distribution of tamoxifen and its metabolites in rat and human tissues during steady-state treatment. Cancer Res 51:4837-4844.

Lim YC, Desta Z, Flockhart DA, and Skaar TC (2005) Endoxifen (4-hydroxy- $N$-desmethyltamoxifen) has anti-estrogenic effects in breast cancer cells with potency similar to 4-hydroxytamoxifen. Cancer Chemother Pharmacol 55:471-478.

Lim YC, Li L, Desta Z, Zhao Q, Rae JM, Flockhart DA, and Skaar TC (2006) Endoxifen, a secondary metabolite of tamoxifen, and 4-OH-tamoxifen induce similar changes in global gene expression patterns in MCF-7 breast cancer cells. J Pharmacol Exp Ther 318:503-512.

Liu Y, Apak TI, Lehmler HJ, Robertson LW, and Duffel MW (2006) Hydroxylated polychlorinated biphenyls are substrates and inhibitors of human hydroxysteroid sulfotransferase SULT2A1. Chem Res Toxicol 19:1420-1425.

Liu Y, Lien IF, Ruttgaizer S, Dove P, and Taylor SD (2004) Synthesis and protection of aryl sulfates using the 2,2,2-trichloroethyl moiety. Org Lett 6:209-212.

Lyon ES, Marcus CJ, Wang JL, and Jakoby WB (1981) Hydroxysteroid sulfotransferase. Methods Enzymol 77:206-213.

Mani C, Hodgson E, and Kupfer D (1993) Metabolism of the antimammary cancer antiestrogenic agent tamoxifen. II. Flavin-containing monooxygenase-mediated N-oxidation. Drug Metab Dispos 21:657-661.

Nose Y and Lipmann F (1958) Separation of steroid sulfokinases. J Biol Chem 233:1348-1351. Phillips DH, Carmichael PL, Hewer A, Cole KJ, and Poon GK (1994) $\alpha$-Hydroxytamoxifen, a metabolite of tamoxifen with exceptionally high DNA-binding activity in rat hepatocytes. Cancer Res 54:5518-5522.

Rainey WE and Nakamura Y (2008) Regulation of the adrenal androgen biosynthesis. J Steroid Biochem Mol Biol 108:281-286.

Riches Z, Stanley EL, Bloomer JC, and Coughtrie MW (2009) Quantitative evaluation of the expression and activity of five major sulfotransferases (SULTs) in human tissues: the SULT "pie". Drug Metab Dispos 37:2255-2261.

Rižner TL (2013) Estrogen biosynthesis, phase I and phase II metabolism, and action in endometrial cancer. Mol Cell Endocrinol 381:124-139.

Rubin GL, Harrold AJ, Mills JA, Falany CN, and Coughtrie MW (1999) Regulation of sulphotransferase expression in the endometrium during the menstrual cycle, by oral contraceptives and during early pregnancy. Mol Hum Reprod 5:995-1002.

Ruddy KJ, Desantis SD, Gelman RS, Wu AH, Punglia RS, Mayer EL, Tolaney SM, Winer EP, Partridge AH, and Burstein HJ (2013) Personalized medicine in breast cancer: tamoxifen, endoxifen, and CYP2D6 in clinical practice. Breast Cancer Res Treat 141:421-427.

Sekura RD (1981) Adenosine 3'-phosphate 5'-phosphosulfate. Methods Enzymol 77:413-415 DOI: $10.1016 /$ S0076-6879(81)77055-1.

Senggunprai L, Yoshinari K, and Yamazoe Y (2009) Selective role of sulfotransferase 2A1 (SULT2A1) in the N-sulfoconjugation of quinolone drugs in humans. Drug Metab Dispos 37: $1711-1717$.

Sheng JJ, Sharma V, and Duffel MW (2001) Measurement of aryl and alcohol sulfotransferase activity. Curr Protoc Toxicol 8(4.5):4.5.1-4.5.9. DOI: 10.1002/0471140856.tx0405s08.

Shibutani S, Dasaradhi L, Terashima I, Banoglu E, and Duffel MW (1998a) Alphahydroxytamoxifen is a substrate of hydroxysteroid (alcohol) sulfotransferase, resulting in tamoxifen DNA adducts. Cancer Res 58:647-653.

Shibutani S, Ravindernath A, Suzuki N, Terashima I, Sugarman SM, Grollman AP, and Pearl ML (2000) Identification of tamoxifen-DNA adducts in the endometrium of women treated with tamoxifen. Carcinogenesis 21:1461-1467.

Shibutani S, Shaw PM, Suzuki N, Dasaradhi L, Duffel MW, and Terashima I (1998b) Sulfation of alpha-hydroxytamoxifen catalyzed by human hydroxysteroid sulfotransferase results in tamoxifen-DNA adducts. Carcinogenesis 19:2007-2011.

Shibutani S, Suzuki N, Terashima I, Sugarman SM, Grollman AP, and Pearl ML (1999) Tamoxifen-DNA adducts detected in the endometrium of women treated with tamoxifen. Chem Res Toxicol 12:646-653.

Singh MN, Stringfellow HF, Walsh MJ, Ashton KM, Paraskevaidis E, Abdo KR, Martin-Hirsch PL, Phillips DH, and Martin FL (2008) Quantifiable mRNA transcripts for tamoxifenmetabolising enzymes in human endometrium. Toxicology 249:85-90.

Surh Y-J and Miller JA (1994) Roles of electrophilic sulfuric acid ester metabolites in mutagenesis and carcinogenesis by some polynuclear aromatic hydrocarbons. Chem Biol Interact 92:351-362.

Address correspondence to: Dr. Michael W. Duffel, College of Pharmacy, University of lowa, 115 S. Grand Ave., lowa City, IA 52242. E-mail: michael-duffel@ uiowa.edu 